\title{
Updating of topographic maps in Nepal
}

\author{
Kalyan Gopal Shrestha \\ Chief Survey Officer
}

\begin{abstract}
The latest Topographical maps in Nepal are over a decade old. The "ideal" mapping product is one which is produced in real time from an updated spatial database. There is an urgent need to update existing ones. A complete and renewed process of updating databases, in traditional and conventional methods, is expensive, time-consuming and demands a great deal of human and capital resources. Therefore, it is impossible to update maps quickly by traditional and conventional methods. The Topographical Survey Branch of Survey Department is updating topographical maps using satellite imagery. It is preferable to focus on the continuous updating of the spatial database, with well defined specifications. In this paper, the updating of topographical maps in Nepal using satellite imagery is discussed.
\end{abstract}

\section{Introduction}

The Survey Department of Nepal has prepared the topographic maps of Nepal. Depending upon the terrains of the country there are two kinds of national topographic map series. These are 1:25,000 maps of middle mountains and Tarai and 1:50,000 maps of high mountainous and Himalayan region.

The Topographic map gives idea about surface features including relief, vegetation cover, water bodies or topography by means of contour lines, shading, hatching, or other graphic devices. A large-scale topographic map even includes the locations of haats (market-places), petrol-pumps, education institutes, rural narrow roads, etc. Meanwhile, the modern world is very dynamic: cities are growing, new settlements appear, new roads, communications networks and engineering facilities are being constructed, new areas of natural resources are being developed, forests are cut, and land use structure is changing. Therefore, topographic maps are always subject to updating. The Survey Department of Nepal, being the national surveying \& mapping organization, has the sole authority to survey, prepare and update the topographic maps of Nepal.

\section{Background}

Some decades before Topographical maps of Nepal at the scale of one inch to one mile or 1: 63,360 maps, popularly known as One inch map series, made by Survey of India during the period 1960s-1970s were in use. The second series of Topographical maps of Nepal were prepared by Survey Department of Nepal. In 1991, with the technical and financial assistance of Japanese Government, Survey Department prepared 81 sheets of topographical maps at the scale of 1:25,000 for Lumbini Zone using aerial photographs of 1989. And later on Topographical maps series for the rest of 13 zones have also been prepared using photogrammetric method with the technical and financial assistance of Finland Government during the period of 1992-2001 at the Scale of 1:25,000 (509 sheets) for Tarai and middle mountainous area and 1:50,000 (116 sheets) for high mountainous and Himalayan area. Thus, the total number of Topographical maps covering whole the country is 706 sheets.

\section{Need For Updating Topographic Maps}

Since land is the foundation for any development activities all the planners and decision-makers naturally expect for the updated mapping, hence the importance of an updated map or topographical database can be easily realized. Therefore, regular updating of Topographical map is most essential to the future development planning of a nation. If updated base map data is either absent or inaccessible, map-users may rely upon outdated (paper) maps. These deficiencies can adversely impact the planning and implementation of development projects. 
Up-to-date topographic maps are the basic tool for environmental analyses, rural and urban development, land use policy, warning and mitigation of natural disasters, infrastructure development etc. According to international studies topographical maps may, if they are effectively used and depending on the sector, improve the effectiveness of the investment and reduce implementing costs of development works.

The usual update rate for the topographic maps ranges from ten to twenty years. As the existing base maps of Lumbini Zone and Eastern Zones have been over a decade, the Survey Department has initiated a program for total updating of the base maps 1:25,000 of Lumbini Zone since a couple of years. The Survey Department, as a national surveying and mapping agency, bears responsibility to give the updated geo-information of the country to support multi-sector development activities.

Many changes have occurred since the first edition in 1992. Hence, need for updating of map series is an essential task. The updating will include more accurate topographic data collected with advanced technologies, information on the changing land cover, the improved transportation network, the expanding built-up areas and other land uses. Also in some other cases there are mistakes in the topographic maps that have to be located and corrected. The ideal case is to update areas with a high rate of change more frequently. The updated material should be presented in any new series of maps.

Consequently, it is crucial to change the updating process to one that is faster, more efficient, modern, and will take all map series into consideration. Updating will be very easy once we already have digital database. Modern and efficient geo-information can be obtained from the remote sensing technology. In the present context it is realized that the integration of GIS and RS (remote sensing) technology is important and appropriate for updating maps.

\section{Approaches for Updating}

Map updating was achieved, at first, by graphical, manual techniques only; then computerised methods were developed, aided by peripheral equipment such as scanners and digitizers. These interactive methods involve intensive manpower. Today, in the digital and computerised era, updating of digital databases, in theory and in practice, is evolving for a wide range of applications, in addition to mapping purposes. Several methods are in use: establishing a new national GIS database, by re-mapping rather than digitising existing maps; producing huge, unique and unified databases in large scale; working on large-scale updating and maintenance. The main approach lately, involves automatic change detection and incremental updating of periodic changes which occurred on the earth surface. Aerial photos and satellite imagery are both used in the interpretation of different features and automatic change detection,

There are two major approaches for updating spatial databases:

- remapping the entire area, establishing a new, alternate, and updated database, which will replace the old one,

- remapping limited areas, incorporating the new data into the available database.

Many subjects are discussed in dealing with maintenance and updating spatial data. For example:

- enhancement of linear features to update transportation networks,

- automatic extraction of geographical objects (roads and buildings) and their integration into an existing Information System ,

- utilisation of the image processing techniques for identification, interpretation, segmentation and matching among objects in known built areas,

- automatic interpretation and extraction of visible, spatial topographic objects from imagery .

\section{Selection of Methods}

Nowadays, several countries in the world face problems in relation to outdated topographic maps. As a consequence there is the necessity to apply methodologies which allow map updating in a faster and more efficient fashion. Aerial photos have been traditionally used as the primary source for the topographic maps making and updating. Aerial photography is season dependent and not reasonably carried out for small area.

After the digital revolution and the beginning of computerassisted map processing, geographic information entered a new era a few years ago: with the arrival on the public market of very-high-resolution digital satellite images, which in theory allows large-scale maps of everywhere to be made while remaining seated in one's office. This revolution in geographic information is in fact a combination of many factors such as increasing powerful computers at a cheaper price, more and more efficient processing software, and the availability of very-highresolution satellite images. Satellite-based digital images 
open new horizons: cheaper imagery, increased territory coverage and decreased relief distortions. Besides, generalization on the small-scale maps becomes simpler: instead of time-consuming simplification of large-scale maps, it is possible to use space images directly. Therefore, satellite-based imagery is used increasingly wider and may soon become the principle method of topographic maps updating. New satellite images with higher resolution give new possibilities for using the technology as a source for updating topographic maps.

One of the great advantages of satellite imagery is the ease of access to areas which have previously been too remote or too dangerous to reach using conventional aerial photography. Owing to this fact satellite images have been considered as an information source which presents several advantages:

1) speed in the process of obtaining updated information: Remotely sensed images of a specific site can be collected with very short revisit time.

2) relatively precise and consistent spatial information: Possibility to apply faster updating methodologies than the traditional photogrammetric process; and Data integration is easier.

3) high temporal resolution and multiple use: With few exceptions (e.g., EROS-B), satellite data are multispectral, so value-added products can also be used for thematic mapping purposes.

4) fairly low costs:

A single satellite scene covers a large area (from less than $65 \mathrm{~km}^{2}$ for OrbView-3 to more than $270 \mathrm{~km}^{2}$ for QuickBird). Availability of higher resolution imagery at reasonable price has heightened the possibility of application of Remote sensing imagery.

In Nepal too, Remote sensing technology is highly relevant. Large areas of Nepal are not easily accessible for ground survey. New aerial photography for whole the country costs relatively expensive to Satellite Imagery. Making aerial flight for a particular required area is virtually impossible. But in case of satellite imagery, the latest image can be procured for just the required area.

\section{The Present Situation}

Survey Department has already National Geographic Information Infrastructure (NGII) and completed the production of digital topographical database based on the latest available topographic maps. Survey Department has started to provide digital topographical data base to governmental and non-governmental map user agencies. These data are available in both hard copy and soft copy format.

Topographical Survey Branch of Survey Department has initiated the Remote Sensing Technology in digital data generation. The Branch has softwares like Photogrammetric Suit, PC Arc/INFO (USA), ArcView (USA) and ERDAS Imagine Professional software version 9.2 and is doing updating Topographical maps of Lumbini Zone since a couple of years with the resources in hand. The main objectives of updating works are focused on updating National Topographical Database and publishing latest printed maps.

Images used so far are IKONOS, IRS and ALOS at different periods of time. There are in total 81 sheets to be updated in Lumbini Zone. Because of limited budget and limited skilled human resources the pace of progress is very slow. So far 36 sheets have been updated, out of which field verifications of 15 sheets have been completed recently. Due to the political conflict existed field verification program was halted for some years. These verified sheets are yet to be finally edited for the final printing. 10 sheets are in progression this year. The present updating works should be extensively expedited to satisfy the real meaning of updating 706 sheets of topographical maps of the entire country and needs of the map users.

\subsection{Issues}

The Survey Department is facing some problems of resources :-

- Human Resources: Since the most of staffs working in digital mapping are just confined to GIS, many staffs are left to be trained for RS. Some of those have trained abroad and some others were trained on-the-job from few weeks to a month. Since the procedures involve mathematical calculations, programming and other unpredictable jobs highly skilled manpower should be allocated for this work. Existing working environment lacks general specification, working manual and time frame for the job. Motivations to employed staff are also to be taken into account.

- Computers and software: The quantities of computers are not sufficient to expedite the pace of work. Map updating job by remote sensing generally associated with mainly two types of software: Image 
processing software and GIS software. The powerful GIS software packages are not fully exploited and presently limited to Cartographic Digital Database. Further, the Remote Sensing section needs to keep pace with the technical advancement and adapt to changes in terms of hardware and application software.

- Image: Lower resolution image are not so effective for quality updating. High resolution image are expensive. Currently, the branch is using image of $2.5 \mathrm{~m}$ resolution, efficient for the standard scale of 1:50 000 and 1:25 000 .

\section{The Methodology}

The latest satellite imagery of required area of required spectral and spatial resolution is purchased. Then these imageries will be rectified geometrically. The job begins with the Automatic Aerial Triangulation, stereo restitution, and digitization of satellite images. As draft prints are prepared, Field Verification will be performed before the finalization of updating. Missed information will be collected during field verification and thus collected information are incorporated in the updated work. After the completion of updating work, hard copy maps will be printed for public use as per the designed national specification with appropriate symbols.

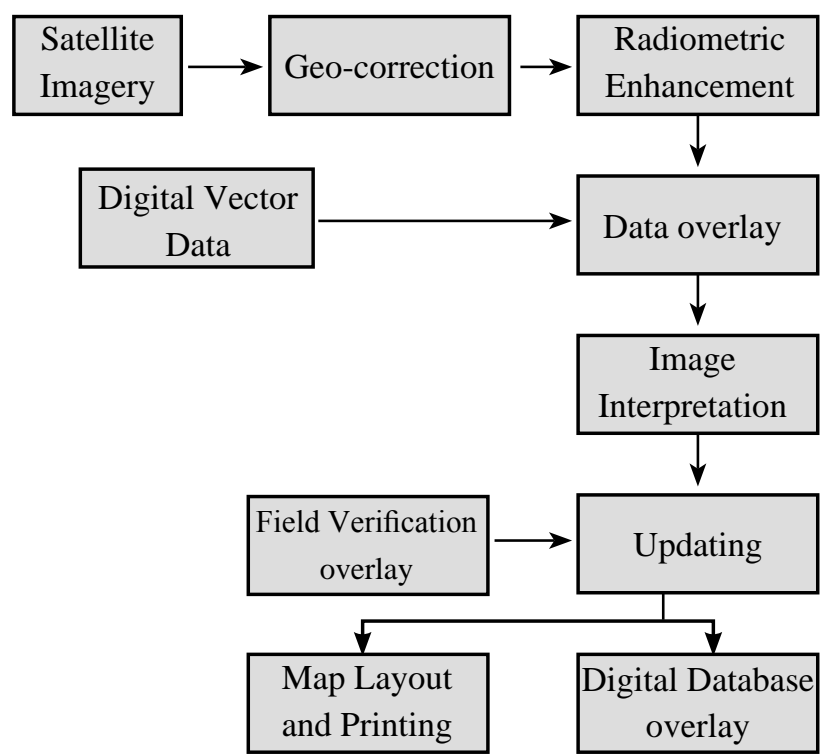

Figure: 1 Flow chart for map updating

\section{Solutions}

Importance of up-to-date topographical digital data is realized by every concerned people now a day. But the present pace of progress seems far lagging behind to meet the real sense of updating national topographical map series. The updating process should be framed with the aim of completing updating maps of whole country in five years. The process is planned to be implemented in three phases.

During the first phase, System and Infrastructure Development works will be performed. Management of Hardwares, Image processing Softwares and Humanwares are accomplished. Procurement of high-resolution satellite imagery for the entire country will be followed by collection of ancillary data. A huge investment will be incurred at this phase.

The second phase will cover updating works, field verifications and incorporation of thus verified information. The final phase will conclude with editing and final printing of maps. Ultimately the updated geo-information will help greatly in effective planning, decision making, managing limited natural resources, etc.

Apart from updating of existing topographical maps of the entire nation we expect some other benefits from this work. As we acquire high-resolution satellite imagery for the entire country, these data subsequently can also be used for other possible products. Consequently the updating works will also support indirectly to fulfill some of our additional objectives as follows:-

- Prepare various kinds of thematic maps.

- Prepare new land resource maps.

- Help establishment of Standards and Specifications.

- Help improve technical capacity building of Survey Department..

- Help create DEMs and orthoimages for many analysis applications.

- Help reduce investment cost in development works in a long run.

\section{Conclusion}

The significance of updated map can not be overlooked in the present context when the nation is striving hard for framing a new Nepal. Only with the received budget at hand the objective of updating topographical maps of the entire country in five years seems hardly to be fulfilled. At a time, when Nepal is facing financial hardship due to post political conflict, the country will not be in position to allocate sufficient budget to expedite this mission. The most part of the budget at present is being invested in reestablishment of the development infrastructures. The 
effective, smooth and successful implementation of this mission requires technical and financial assistance from the international donor agency.

\section{References}

1. David Holland (corresponding author), Paul Marshall, Updating Maps in a Well-mapped country Using High Resolution Satellite Imagery, Ordnance Survey, Romsey Road, Southampton, SO16 4GU UK

2. Jagat Raj Poudel and Nab Raj Subedi, Remote Sensing and Space Technology Application in Topographic Mapping and Maps Updating, Colloquium on the Role and Functions of Survey Department in the Context of Broader Technological Development, Kathmandu, March 4-5, 2005
3. Kumar, M. and Castro, O., 2001, Practical Aspects of Ikonos Imagery for Mapping, article published on the 22nd Asian Conference on remote sensing

4. Michael Tonon, SPOT 5 data for line map updating: New perspectives in mapping, GIS Development

5. Prof. Gottfried Koneeny, Mapping from Space, University of Hanover, Germany, 2002, article published on the 23rd ACRS Proceedings, Kathmandu, Nepal.

6. Tirtha B. Pradhanang, Topographical Survey Branch with Remote sensing, article published on the 23rd ACRS Proceedings, Kathmandu, Nepal 